\title{
Incidence and risk factors associated with ectopic pregnancy: a prospective study
}

\author{
Harish K. M. ${ }^{1}$, Shwetha N. ${ }^{1 *}$, Nalini N. ${ }^{2}$
}

\begin{abstract}
${ }^{1}$ Department of Obstetrics and Gynaecology, The Apollo Medical College, Chittoor, Andhra Pradesh, India
${ }^{2}$ Department of Obstetrics and Gynaecology, Govt District Hospital, Ramanagara, Karnataka, India
\end{abstract}

Received: 09 December 2020

Accepted: 24 December 2020

\author{
*Correspondence: \\ Dr. Shwetha N, \\ E-mail: shwethanarasappa@gmail.com
}

Copyright: () the author(s), publisher and licensee Medip Academy. This is an open-access article distributed under the terms of the Creative Commons Attribution Non-Commercial License, which permits unrestricted non-commercial use, distribution, and reproduction in any medium, provided the original work is properly cited.

\begin{abstract}
Background: Increased incidence of ectopic pregnancy and its impact on women's fertility in recent years need significant attention.

Methods: A two years prospective study from January 2018 to December 2019 conducted to determine incidence, association of risk factors with ectopic pregnancy and find the most common risk factor of ectopic pregnancy in department of obstetrics and Gynaecology, a tertiary care Hospital in Pune.

Results: During the study period 100 patients were diagnosed to have ectopic pregnancy. Incidence was 5.29 per 1000 births. Majority were in the age group of 20-24 years (42\%), multiparous (59\%) and belong to low socioeconomic state $(62 \%)$. In majority of the patients $(22 \%)$ no risk factors was found. Among the patients who had risk factors, the main risk factors for ectopic pregnancy were history of history of pelvic inflammatory disease (20\%), previous tubal/abdominal surgery (12\%), history of Infertility (10\%), previous termination of pregnancy (10\%), contraception with mirena IUS or IUCD in situ $(8 \%)$ and a history of prior ectopic pregnancy $(4 \%)$.

Conclusions: In majority $(78 \%)$ of patients risk factors for ectopic pregnancy was present and pelvic inflammatory disease was found to be a major risk factor for ectopic pregnancy.
\end{abstract}

Keywords: Ectopic, PID, Fallopian tube

\section{INTRODUCTION}

The earliest accurate description of an extra uterine pregnancy was that of Albucasis, an Arabian physician who lived in Spain in the 11th century. In his case, described by Kasper Bauhan in 1586, the foetal parts were discharged through the umbilicus following the death of an abdominal pregnancy. This marked the 'Great Albucasis Evolution'. In 1693, Busiere first recognized ectopic pregnancy when he was examining the body of a prisoner executed in Paris. ${ }^{1}$

Ectopic pregnancy is any pregnancy in which the fertilized ovum implants outside the intrauterine cavity. More than 95 percent of ectopic pregnancies occur in the fallopian tubes. Another 2.5 percent occur in the cornua of the uterus, and the remainder are found in the ovary, cervix or abdominal cavity. ${ }^{2}$ Because none of these anatomic sites can accommodate placental attachment or a growing embryo, the potential for rupture and haemorrhage always exists. A ruptured ectopic pregnancy is a true medical emergency. It is the leading cause of maternal mortality in the first trimester and accounts for 10 to 15 percent of all maternal deaths. ${ }^{3}$

The prevalence of risk factors for ectopic pregnancy are increasing, accounting, in part, for the increased ectopic pregnancy incidence. Further, the increased incidence of ectopic pregnancy may be the result of earlier diagnosis, with the use of sensitive pregnancy tests and transvaginal ultrasound detecting some ectopic pregnancies that in the past may have resolved spontaneously before diagnosis. ${ }^{4}$ 
The increased incidence of EP, and variance in population structure and regional differences, the risk factors of EP may have changed. Additionally, due to the increased incidence in infertility, currently approaches such as assisted reproduction technology (ART) are more widely used; therefore, their role and strength in the incidence of EP should be re-evaluated. ${ }^{5}$

\section{Aims and objective}

To find the incidence of ectopic pregnancy. To find the common risk factors associated with ectopic pregnancy.

\section{METHODS}

This prospective study was conducted at a tertiary care Hospital, Pune, for a period of 2 years from January 2018 to December 2019. All the patients diagnosed as ectopic pregnancy are included in the study. Patients with intrauterine pregnancy or abortion are excluded from study. Ectopic pregnancy will be diagnosed with clinical examination, urine pregnancy test and radiological investigation. Ectopic pregnancy will be confirmed by beta-human chorionic gonadotropin (HCG) levels with transvaginal sonography and laparoscopy/laparotomy. Following variables will be documented: total number of ectopic pregnancies and live births during study period, total, maternal age, parity, socioeconomic state history of previous ectopic pregnancy, previous tubal surgery, history of infertility, contraception with mirena IUS or IUCD in situ, history of smoking, previous pelvic or abdominal surgery, previous termination of pregnancy, previous spontaneous miscarriages, history of assisted conception/IVF, conception while using progesterone only pill, emergency contraception use in current pregnancy, early age of first intercourse $>18$ years. Incidence will be calculated per 1000 live birth and remaining data will be analysed statistically.

\section{RESULTS}

In present study the total number of deliveries was 18,871 , and the total number of ectopic pregnancies were 100; giving an incidence of 5.29 per 1000 live births.

Table 1: Incidence of ectopic pregnancy.

\begin{tabular}{|lll|}
\hline $\begin{array}{l}\text { Total ectopic } \\
\text { pregnancy } \\
\text { during study } \\
\text { period }\end{array}$ & $\begin{array}{l}\text { Total number } \\
\text { of live birth }\end{array}$ & $\begin{array}{l}\text { Incidence of } \\
\text { ectopic } \\
\text { pregnancy per } \\
1000 \text { births }\end{array}$ \\
\hline $\mathbf{1 0 0}$ & 18,871 & 5.29 \\
\hline
\end{tabular}

It was found that the majority of ectopic pregnancies, that is $53.22 \%$, occurred in the women in the age group 20-24 years. Multiparous women (59\%) accounted for the maximum number of ectopic pregnancies. Also most of patients with ectopic pregnancy belonged to low socioeconomic status $(62 \%)$.
Table 2: Comparison of incidence.

\begin{tabular}{|lll|}
\hline Studies & Year & Incidence \\
\hline Lakshmi et al $^{\mathbf{6}}$ & 2017 & 4.8 \\
\hline Madan et al $^{\mathbf{7}}$ & 2017 & 5.1 \\
\hline Mishra et al $^{\mathbf{8}}$ & 2015 & 5.2 \\
\hline Present study $^{\mathbf{S}}$ & 2019 & 5.2 \\
\hline Shetty et al & 2014 & 5.6 \\
\hline Archana et al $^{\mathbf{1 0}}$ & 2017 & 5.9 \\
\hline Tahmina et al $^{\mathbf{1 1}}$ & 2016 & 9.1 \\
\hline
\end{tabular}

Table 3: Socio-demographic status.

\begin{tabular}{|c|c|}
\hline & No of pregnancies (\%) \\
\hline \multicolumn{2}{|c|}{ Maternal age (in years) } \\
\hline$<20$ & $11(11)$ \\
\hline $20-24$ & $42(42)$ \\
\hline $25-29$ & $27(27)$ \\
\hline $30-34$ & $18(18)$ \\
\hline $35-39$ & $2(2)$ \\
\hline$\geq 40$ & $0(0)$ \\
\hline \multicolumn{2}{|l|}{ Parity } \\
\hline Primipara & $41(41)$ \\
\hline Multipara & $59(59)$ \\
\hline \multicolumn{2}{|c|}{ Socioeconomic Status } \\
\hline Low & $62(62)$ \\
\hline Middle & $32(32)$ \\
\hline High & $6(6)$ \\
\hline
\end{tabular}

Table 4: Risk factors associated with ectopic pregnancy.

\begin{tabular}{|ll|}
\hline Risk factors & $\begin{array}{l}\text { No. of } \\
\text { patients } \\
(\%)\end{array}$ \\
\hline No. risk factors & $22(22)$ \\
\hline H/O pelvic inflammatory disease & $20(20)$ \\
\hline Previous tubal/abdominal surgery & $12(12)$ \\
\hline H/O infertility & $10(10)$ \\
\hline Previous termination of pregnancy & $10(10)$ \\
\hline Surgical & $6(6)$ \\
\hline Medical & $1(1)$ \\
\hline Both surgical and medical & $3(3)$ \\
\hline $\begin{array}{l}\text { Contraception with mirena IUS or } \\
\text { IUCD in situ }\end{array}$ & $8(8)$ \\
\hline Previous ectopic pregnancy & $4(4)$ \\
\hline 1 previous ectopic pregnancy & $3(3)$ \\
\hline$\geq 2$ previous ectopic pregnancy & $1(1)$ \\
\hline h/o assisted conception/IVF & $4(4)$ \\
\hline Previous spontaneous miscarriages & $3(3)$ \\
\hline $\begin{array}{l}\text { Conception while using progesterone } \\
\text { only pill }\end{array}$ & $2(2)$ \\
\hline $\begin{array}{l}\text { Emergency contraception use in current } \\
\text { pregnancy }\end{array}$ & $2(2)$ \\
\hline \begin{tabular}{l} 
Early age of first intercourse $\leq 18$ years \\
\hline H/O smoking
\end{tabular} & $2(2)$ \\
\hline
\end{tabular}


In $22 \%$ of patients with ectopic pregnancy, no risk factors were identified. Among the remaining $78 \%$ of patients who had risk factors for ectopic pregnancy, $20 \%$ of patients had pelvic inflammatory disease and was considered to be most common risk factor. Previous tubal/abdominal surgery $(12 \%)$ was found to be second most common risk factor. History of Infertility and Previous termination of pregnancy (mainly surgical) each contributed $10 \%$ as risk factors for ectopic pregnancy. Eight per-cent of ectopic pregnancy was due to Contraception with mirena IUS or IUCD in situ. Previous ectopic pregnancy and history of assisted conception/IVF each was found in $4 \%$ of patients with ectopic pregnancy. Previous spontaneous miscarriages were seen in $3 \%$ of patients. Risk factors such as conception while using progesterone only pill, Emergency contraception use in current pregnancy, Early age of first intercourse $<18$ years each was seen in $2 \%$ of patients with ectopic pregnancy. History of smoking was seen in $1 \%$ of patients.

\section{DISCUSSION}

The word "ectopic" means "out of place". An ectopic pregnancy occurs when a fertilized ovum implants outside the normal uterine cavity. The most common site for ectopic pregnancy adherence is in the ampullary region of the fallopian tube. The estimated rate of ectopic pregnancy in the general population is 1 to $2 \%$ and 2 to $5 \%$ among patients who utilized assisted reproductive technology. ${ }^{12}$

Centers for Disease Control (CDC) USA 1 have reported a 4-fold increase in its incidence from 1970 to $1983,4.5$ to 16.18 per 1000 pregnancies. In a multicentric case-control study in India, (ICMR Task Force Project, 1990) the incidence of ectopic pregnancy is 3.12 per 1000 pregnancies or 3.86 per 1000 live births. In present study, during the period of two year, there were a total of 18,871 deliveries and 100 cases of ectopic pregnancies were documented giving the incidence of ectopic pregnancies of $5.2 / 1000$ deliveries. Comparison of incidence in various studies is given in table 2 .

In the present study majority of cases belonged to age group of 20-24 years (42.0\%) similar to most of the studies from developing countries. Younger age group has high prevalence because they are more active sexually, predisposed to STI, PID and their sequelae.

Compared to ICMR multi-centric case control study of ectopic pregnancy, in which majority of women were young and had low parity, in the present study, ectopic pregnancy was seen predominantly in higher birth order. Multiparous women were found to be more prone to have ectopic pregnancy $(61 \%)$ in LaxmiKarki et al study. ${ }^{13}$ Majority of patients belonged to low socioeconomic status. Because of poor hygiene in low socioeconomic status patients, they are at higher risk of pelvic inflammatory disease.

In present study, no risk factors were identified in $22 \%$ of women with ectopic pregnancy. Although women with ectopic pregnancy frequently have no identifiable risk factors, a prospective case-controlled study has shown that increased awareness of ectopic pregnancy and a knowledge of the associated risk factors helps identify women at higher risk in order to facilitate early and more accurate diagnosis. Most risk factors are associated with risks of prior damage to the Fallopian tube. These factors include any previous pelvic or abdominal surgery, and pelvic infection. ${ }^{14}$ Chlamydia trachomatis has been linked to $30-50 \%$ of all ectopic pregnancies. ${ }^{15}$

History of Pelvic inflammatory disease (PID) was seen in $20.0 \%$ of our patients making it most common risk factor for ectopic pregnancy, quite higher to that reported by Singh et al, and Mufti et al, in their studies. Present study justifies Cates et al which state that in the general population, pelvic inflammatory disease is the most common risk factor for ectopic pregnancy. ${ }^{16-18}$ Organisms that preferentially attack the fallopian tubes include Neisseria gonorrhoeae, Chlamydia trachomatis and mixed aerobes and anaerobes can produce tubal damage. Vaidya found PID as the commonest risk factor with an incidence of $25 \%$ in their study of 192 cases of ectopic pregnancy. ${ }^{19}$

Previous tubal/abdominal surgery (12\%) causing tubal damage was second most common risk factor ectopic pregnancy in present study compared to study by Patel et al in which they found that $30.8 \%$ of cases had ectopic pregnancy following tubal ligation. ${ }^{20}$

Ectopic pregnancy was seen with history of infertility in $10 \%$ and history of termination of pregnancy in $10 \%$ of patients in present study. Clayton et al found that in recent years, the incidence of ectopic pregnancy is on the rise in women attending infertility clinics even in the absence of tubal disease. ${ }^{21}$ In vitro, fertilization is associated with an ectopic pregnancy risk of $2-5 \%$ and even higher if associated with the tubal disease. Virk et al found no evidence that a previous medical abortion, as compared with a previous surgical abortion, increases the risk of ectopic pregnancy. ${ }^{22}$ Spontaneous abortion contributed to $3 \%$ of ectopic pregnancy in present study.

Contraception with mirena IUS or IUCD in situ accounted for $8 \%$ and conception while using progesterone only pill accounted for $2 \%$ of ectopic pregnancy in present study. Certain types of contraception have been implicated as a risk for occurrence of EP. Gandotra et al found that although contraceptive methods like barrier and oral contraceptives was found to lower the risk, contraceptive methods like POP (OR 7.19) and IUCD (OR 3.55) were found to increase the risk for ectopic pregnancy. ${ }^{23}$

Emergency contraception use in current pregnancy accounted for $2 \%$ of ectopic pregnancy in present study. Jain et al found that hormonal emergency contraceptive pills failure rate is high when used in periovulatory period with increased chance of EP. ${ }^{24}$

History of previous ectopic pregnancy contributed $4 \%$ to the current ectopic pregnancy in present study. Women whose first pregnancy is ectopic are likely to have fivefold increased risk of a subsequent ectopic pregnancy. ${ }^{25}$ 
Early age of first intercourse predisposes women to sexually transmitted disease, thereby increasing risk of ectopic pregnancy. Early age of first intercourse accounted $2 \%$ risk of ectopic pregnancy in present study. Because of cultural restriction in present study population, incidence of smoking is less or history of smoking is not revealed. Only $2 \%$ of patients who smoke had ectopic pregnancy in present study.

\section{CONCLUSION}

Incidence of ectopic pregnancy in present study is unchanged as compared to majority of other recent studies given in table 2. PID is the major etiological factors for ectopic pregnancy in our setup. Advancing maternal age and low socioeconomic status are risk factor for ectopic pregnancy possibly due to increased chances of exposure to STDs and PID.

\section{Funding: No funding sources}

Conflict of interest: None declared

Ethical approval: The study was approved by the Institutional Ethics Committee

\section{REFERENCES}

1. Te Linde's Operative Gynaecology, 8th ed, Lippincott - Raven, Philadelphia. 1997;501-27.

2. Hankins GD, Clark SL, Cunningham FG, Gilstrap LC. Ectopic pregnancy. In: Operative obstetrics. Norwalk, Conn.: Appleton \& Lange. 1995;437-56.

3. Ectopic pregnancy-United States, 1990-1992. MMWR Morb Mortal Wkly Rep. 1995;44:46-8.

4. PISARSKA, MARGARETA D, CARSON, SANDRA A. Incidence and Risk Factors for Ectopic Pregnancy, Clinical Obstetrics and Gynecology. 1999;42(1):2-8.

5. Malak M, Tawfeeq T, Holzer H, Tulandi T. Risk factors for ectopic pregnancy after in vitro fertilization treatment. J Obstet Gynaecol Can. 2011;33(6):617-9.

6. Lakshmi S, Babita K, Bala HP, Nidhi C. A Retrospective Analysis on Ectopic Pregnancy: A One Year Study. Sch J App Med Sci. 2017;5(8E):3318-23.

7. Madan A, Nitin KH, Kaur A, Neki NS. Ectopic Pregnancy: A life threatening emergency. Int J Curr Res Med Sci. 2017;3(7):144-151.

8. Mishra S, Chaudhary V, Kaul R, Tabassum B. Analysis of 62 Cases of Ectopic Pregnancies in a Rural Medical College Set Up at Nalgonda Telangana, India. Int J Sci Stud. 2015;3(6):103-06.

9. Shetty SK, Anil SK. Innovative Journal of Medical and Health Science. 2014;4(1):305-09.

10. Archana MS, Soumini G. Study Of Ectopics In Emergency Surgical Admissions. Global Journal For Research Analysis. 2017;9(6):2277-8160.

11. Tahmina S, Daniel M, Solomon P. Clinical Analysis of Ectopic Pregnancies in a Tertiary Care Centre in Southern India: A Six-Year Retrospective Study. Journal of Clinical and Diagnostic Research. 2016;10(10):13-16.
12. Panelli DM, Phillips $\mathrm{CH}$, Brady PC. Incidence, diagnosis and management of tubal and nontubal ectopic pregnancies: a review. Fertil Res Pract. 2015;1:15.

13. LaxmiKarki L, Pradhan B, Duwa S. Annual Analysis of Ectopic Pregnancy in Tertiary Care Hospital. PMJN. 2011;11:5-8.

14. Karaer A, Avsar FA, Batioglu S. Risk factors for ectopic pregnancy: a case-control study. Aust N Z J ObstetGynaecol. 2006;46:521-27.

15. Turner C, Horner P. British Fertility Society Impact of Chlamydia trachomatis in the reproductive setting: British Fertility Society Guidelines for practice. Hum Fertil (Camb). 2010;13:115-25.

16. Singh S, Mahendra G, Vijayalakshmi S, Pukale RS. Clinical study of ectopic pregnancy in a rural setup: A two year survey. Natl J Med Res. 2014;4(1):37-39.

17. Mufti S, Rather S, Mufti S, Rangrez RA, Wasiqa K. Ectopic pregnancy: An analysis of 114 cases. JKPract. 2012;17(4):20-23.

18. Cates W, Rolfs RT, Aral SO. Sexually transmitted diseases, pelvic inflammatory disease, and infertility: an epidemiologic update. Epidemiol Rev. 1990;12:199-220.

19. Vyas PS, Vaidya P. Epidemiology, diagnosis and management of ectopic pregnancy - An analysis of 196 cases. BHJ Orig Res Artic. Available from: html: file://e: lepidemiology, diagnosis and management of ectopic pregnancy. Last accessed on 22 August, 2015

20. Patel UM, Gandhi MR, Jani PS, Kakani CR, Thakor N. Clinical profile and management of ectopic pregnancy in patients with ectopic pregnancy at GMERS medical college and hospital Dharpur-Patan, North Gujarat region, India. Int J Res Med Sci. 2015;3:841-5.

21. Clayton HB, Schieve LA, Peterson HB, Jamieson DJ, Reynolds MA, Wright VC. Ectopic pregnancy risk with assisted reproductive technology procedures. Obstet Gynecol. 2006;107:595-604.

22. Virk J, Zhang J, Olsen J. Medical abortion and the risk of subsequent adverse pregnancy outcomes. N Eng $\mathrm{J}$ Med. 2007;357:648-53.

23. Gandotra N, Zargar S. Risk factors associated with ectopic pregnancy in our sociodemographic setup. Int J Reprod Contracept Obstet Gynecol. 2020;9:4150-4.

24. Jain S H, Ghike S, Gawande MS, Joshi SA, Kawthalkar AS, Somalwar SA. LNG Emergency contraceptive pills: Risk factors for pregnancy. J South Asian Feder Obst Gynae. 2013;5(2):87-8

25. European Society of Human Reproduction and Embryology (ESHRE). Women whose first pregnancy was ectopic have fewer children and high risk of another ectopic pregnancy. ScienceDaily. 2012. Available at: www.sciencedaily.com/ releases/2012/10/121018100154.htm. Accessed on 17 November, 2020.

Cite this article as: Harish KM, Shwetha N, Nalini $\mathrm{N}$. Incidence and risk factors associated with ectopic pregnancy: a prospective study. Int J Reprod Contracept Obstet Gynecol 2021;10:703-6. 